\title{
Proprietary Name
}

National Cancer Institute

\section{Source}

National Cancer Institute. Proprietary Name. NCI Thesaurus. Code C71898.

The part of the name or logo associated with a specific product or service identifying and distinguishing it from varieties of the same product or service marketed by competing companies. 